Article

\title{
Printability of the Screen-Printed Strain Sensor with Carbon Black/Silver Paste for Sensitive Wearable Electronics
}

\author{
Xue Qi ${ }^{1}$, Heebo Ha ${ }^{2}$, Byungil Hwang ${ }^{2, *}$ and Sooman Lim ${ }^{1, *}$ \\ 1 Department of Flexible and Printable Electronics, LANL-CBNU Engineering Institute-Korea, \\ Jeonbuk National University, Jeonju 54896, Korea; qixuerhea@jbnu.ac.kr \\ 2 School of Integrative Engineering, Chung-Ang University, Seoul 06974, Korea; hhb2340@gmail.com \\ * Correspondence: bihwang@cau.ac.kr (B.H.); smlim@jbnu.ac.kr (S.L.)
}

Received: 8 September 2020; Accepted: 30 September 2020; Published: 6 October 2020

\begin{abstract}
Printing technology enables not only high-volume, multipurpose, low-impact, low-cost manufacturing, but also the introduction of flexible electronic devices, such as displays, actuators, and sensors, to a wide range of consumer markets. Consequently, in the past few decades, printed electronic products have attracted considerable interest. Although flexible printed electronic products are attracting increasing attention from the scientific and industrial communities, a systematic study on their sensing performance based on printability has not been reported so far. In this study, carbon black/Ag nanocomposites were utilized as pastes for a flexible wearable strain sensor. The effects of the rheological property of the pastes and the pattern dimensions of the printed electrodes on the sensor's performance were investigated. Consequently, the printed sensor demonstrated a high gauge factor of 444.5 for an applied strain of $0.6 \%$ to $1.4 \%$ with a durability of 1000 cycles and a linearity of $\mathrm{R}^{2}=0.9974$. The sensor was also stable under tough environmental conditions.
\end{abstract}

Keywords: strain sensor; rheology; dimension; Ag nanoparticles; carbon black; screen printing

\section{Introduction}

Strain sensors for the detection of applied stress have attracted considerable attention for wearable electronics in the fields of sports, personal health monitoring, soft robots, and prosthetic devices [1-5]. The key factors in determining the performance of a strain sensor are high sensitivity, stability, and low manufacturing cost with simple processability [6]. Although conventional strain sensors with metal foils have been commercialized, they still have the limitations of low sensitivity, high material costs, and complexity of the manufacturing process [7]. In recent years, considerable efforts have been made to develop strain sensors with a high performance and low cost using functional materials. Carbon-based materials, such as graphene and carbon nanotubes, are widely used in strain sensors because of their excellent electrical conductivity and mechanical reliability. S. Ali et al. reported a highly sensitive humidity sensor consisting of silver interdigital electrodes and a graphene/methyl-red composite layer, which is fabricated on a low-cost transparent polyethylene terephthalate (PET) substrate using a commercialized Dimatix Materials printer [8]. J. Lee et al. also investigated a humidity sensor film fabricated by loading large amounts of multi-walled carbon nanotubes (MWCNTs) in a poly(acrylic acid) polymer matrix containing poly(4-styrenesulfonic acid) to enhance MWCNT dispersion [9]. However, the relatively high manufacturing costs of graphene and carbon nanotubes have limited the mass production of such sensors. Alternatively, carbon black (CB) has been employed for manufacturing strain sensors, owing to its high conductivity and low price [10]. However, there are only limited reports on the use of $\mathrm{CB}$ for manufacturing strain sensors. 
The most widely used method to prepare wearable strain sensors with a low cost is to utilize resistive sensors with simple structures. Resistive sensors can be fabricated via printing technology, which enables the mass production of wearable devices with a high flexibility. Among existing printing methods, the screen-printing process has been widely used in the field of electronics and has been successfully employed for various functional pastes and substrates [6,11-16]. Previous studies have proposed various screen-printing methods. The research trend in these studies has evolved toward the development of low-cost, diversified, simple, or low-waste manufacturing processes [6,17-21]. Recently, H. Song et al. have reported a screen-printed strain sensor with CBs [22]. W. Jang et al. have demonstrated a flexible strain sensor with a composite of CB and silver nanoparticles (AgNPs) as the sensing material and thermoplastic polyurethane as the matrix [23]. However, the sensitivities of the reported sensors were low and the effect of printability on their sensitivity was not investigated. In fact, the characteristics of screen-printed strain sensors are highly related to printability, which is affected by the rheological properties of the paste inks and the dimensions of the printed patterns. Several reports on using spherical and/or flake-shaped silver particles/nanowires and carbon-based materials, such as graphite, single-walled carbon nanotubes, and graphene, for resistive-type printed sensors have been published so far $[6,17,21,24,25]$. However, the relationship between the performance of a sensitive strain sensor and printability in the screen-printing process has not been investigated so far.

In this article, we propose a simple and low-cost method to manufacture a flexible and high-performance sensitive strain sensor using $\mathrm{CB} / \mathrm{AgNP}$ composites through a screen-printing process. During the fabrication process, the effects of the rheological property of the paste and the dimensions of the printed pattern are systematically studied to maximize the sensing properties. Consequently, the gauge factor (GF) of the sensor shows a high value of 444.6 with a linearity of $\mathrm{R}^{2}=0.99$. The detection ability of the strain sensor with the CB/AgNPs composite material for human movements, such as finger bending and elbow flexion, is studied as well.

\section{Experiments}

\subsection{Chemicals}

CB was purchased from the graphene market (South Korea). AgNPs were purchased from NTbase (South Korea), and the model of AgNPs was NP-S80 with a purity of 99.99\%. A dispersion (BYK-180) was obtained from BYK (South Korea). 2-(2-Butoxyethoxy) ethyl acetate (99.0\%) and 2-ethoxyethyl acetate $(99.0 \%)$ were supplied by Samchun Pure Chemical Co., Ltd. (Pyeongtaek -si, South Korea). A PET film and silver paint (SPI-Chem) were also used as components of the sensor.

\subsection{Paste Formulation of $\mathrm{CB} / \mathrm{Ag}$ Paste}

An easy, low-cost, and low-temperature chemical solution process was used to prepare the $\mathrm{CB} / \mathrm{Ag}$ paste. The resin, dispersion, and solvent were mixed in the weight ratio of 4:1:8 with the CB solid contents of $3.5,17.5$, and $31.5 \mathrm{wt} \%$. The materials were mixed using a vortex agitator (Daihan Scientific) at $1000 \mathrm{RPM}$ for $3 \mathrm{~h}$. The paste was added to the mixture for $20 \mathrm{~min}$, the mixture was soaked for $5 \mathrm{~min}$, and this process was repeated three times.

\subsection{Fabrication of $C B / A g$ Strain Sensor}

The formulated pastes with different ratios of materials were first loaded onto screen meshes (mesh count 400, Samborn Screen, South Korea) and squeezed with a snap-off distance of $0.3 \mathrm{~mm}$ at a speed of $10 \mathrm{~cm} / \mathrm{s}$ and a pressure of $6.8 \mathrm{~mm}$, as shown in Figure 1a. Then, the printed patterns were dried in a vacuum oven at $120^{\circ} \mathrm{C}$ for $1 \mathrm{~h}$. The printed sensors were connected to a nickel tape and silver paint to evaluate their performance. 
(a)

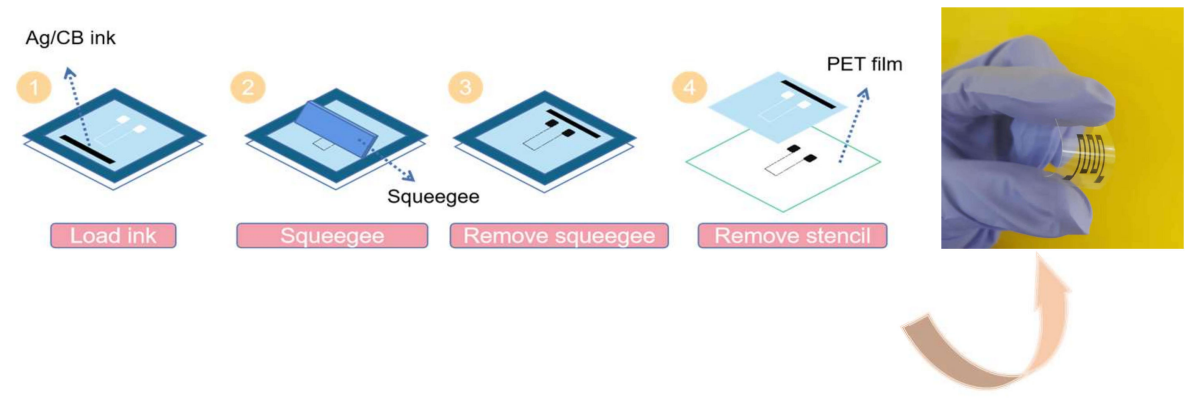

(b)

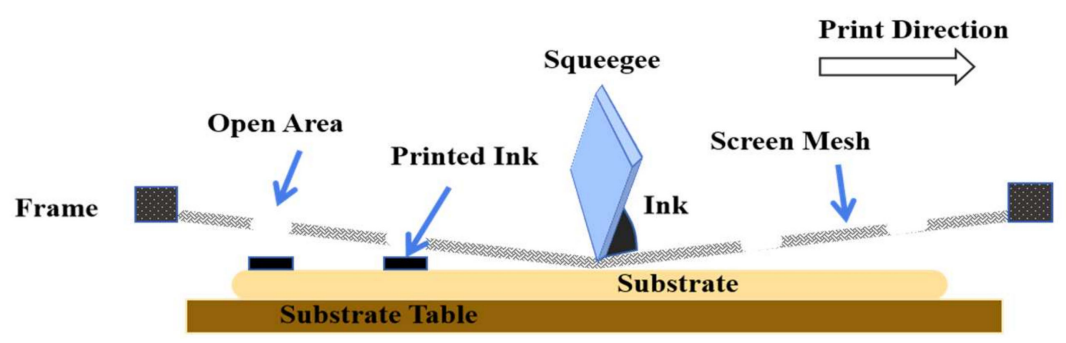

Figure 1. (a) The schematic diagram of printing process and (b) overall working principle with $\mathrm{CB} / \mathrm{AgNPs}$ for wearable strain sensor.

\subsection{Characterization}

A mixed flow instrument (Discovery HR-3, New Castle, USA) was used to measure the viscosity of the Ag/CB ink. A current signal system (SourceMeter, Keithley 2400, Beaverton, USA) of voltage $5 \mathrm{~V}$ was used to test the durability of the sensor with a bending system (OWiS PS 10-32, Staufen, Germany). Optical microscope photographs were obtained using an electron optical microscope (Eclipse LV100ND/LV100NDA, Seoul, Korea). Scanning electron microscope (SEM) images were obtained with a field-emission scanning electron microscope (Carl Zeiss Supra 40VP, Oberkochen, Germany).

\section{Results and Discussion}

Figure $1 \mathrm{~b}$ shows the screen-printing process for the fabrication of the $\mathrm{CB} / \mathrm{AgNP}$-based strain sensor on the PET substrate. After the $\mathrm{CB} / \mathrm{AgNP}$ paste penetrated the substrate through the opening mesh owing to the pressure of the squeeze, the screen mesh was snapped off the substrate by the tension, resulting in the specific pattern of the paste. The rheological property of the $\mathrm{CB} / \mathrm{AgNP}$ paste and the related pattern fidelity should be considered to obtain the desired sensor. Figure 2 shows the rheological behavior of the $\mathrm{CB} / \mathrm{AgNP}$ paste using a cone-plate rheometer to determine the effect of the solid content of $C B$ on the pattern quality. The ratios of $C B / A g N P$ were 9:1, 5:5, and 1:9 for CB/AgNP-L, $\mathrm{CB} / \mathrm{AgNP}-\mathrm{M}$, and $\mathrm{CB} / \mathrm{AgNP}-\mathrm{H}$, respectively. The measured viscosities at different shear rates from the steady-state flow test shown in Figure 2a reveal that all the three pastes exhibit shear-thinning behavior. The viscosity of the paste ink decreased as the shear rate increased from 1.4 to 0.4 Pa.s, 130.4 to 1.0 Pa.s, and 486.0 to 0.4 Pa.s for CB/AgNP-L, CB/AgNP-M, and CB/AgNP-H, respectively. This indicates the suitability of all the formulated inks for the screen-printing process. In addition, the $\mathrm{CB} / \mathrm{AgNP}$ paste ink with a higher solid content of $C B$ exhibited a higher viscosity at zero shear viscosity and above the shear rate, which indicates that the concentration of $\mathrm{CB}$ affects processability during the screen-printing process. Subsequently, a peak hold step (PHS) test involving holding the sample at different shear rates at three intervals, namely, the reference interval (0-30 s), high-shear interval (30-60 s), and regeneration interval (60-150 s), was conducted as shown in Figure $2 \mathrm{~b}$. This process mimics the actual screen-printing process, and the applied stress value varies according to each time interval, which elucidates the paste flow with a viscoelastic feature. The results show the general flow behavior of thixotropy, where a structural transition occurs due to mechanical pressure (through squeezing in this process). In addition, the recovery value of the three pastes to determine the pattern 
fidelity was proportional to the $\mathrm{CB}$ concentration; the recovery values were in the order of $\mathrm{CB} / \mathrm{AgNP}-\mathrm{H}$ $(3.5 \%), \mathrm{CB} / \mathrm{AgNP}-\mathrm{M}(17.5 \%)$, and CB/AgNP-L (31.5\%). These values are listed in Table 1. Figure 2c indicates that the result of the PHS test was significantly related to the pattern fidelity according to the recovery behavior. As the recovery value increased in the order of CB/AgNP-L, CB/AgNP-M, and $\mathrm{CB} / \mathrm{AgNP}-\mathrm{H}$ at the same time interval, the dimensions of the pattern were closer to the desired dimensions, and the line edge sharpness increased. However, the recovery time (leveling time) is also an important factor in printability, as the abrupt recovery of $\mathrm{CB} / \mathrm{AgNP}-\mathrm{H}$ did not yield the best quality, as shown in Figure 2c. In this case, the excessively short recovery time after printing was not suitable for the full leveling of the paste, resulting in an empty spot during evaporation. Moreover, trapping of the paste into the mesh becomes likelier due to the excessively high viscosity. Thus, CB/AgNP-M was chosen as the optimized paste.

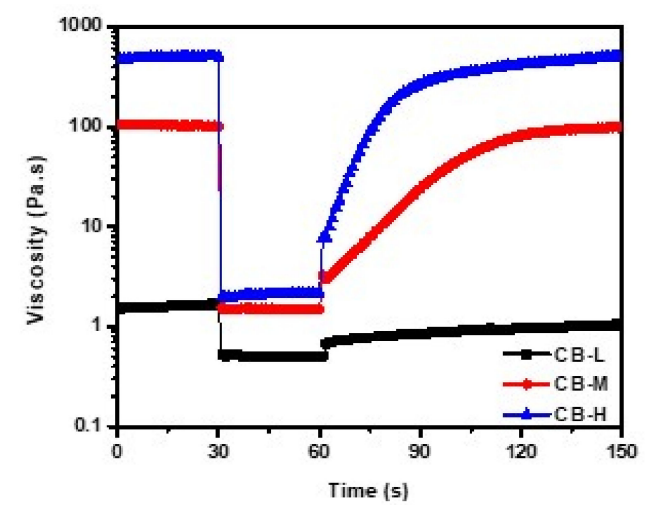

(a)

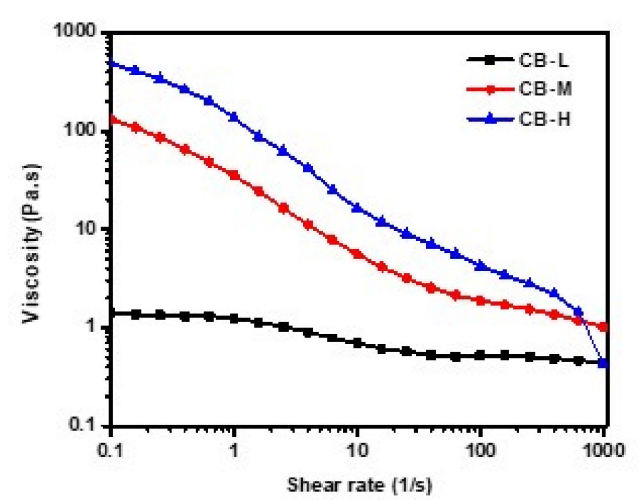

(b)

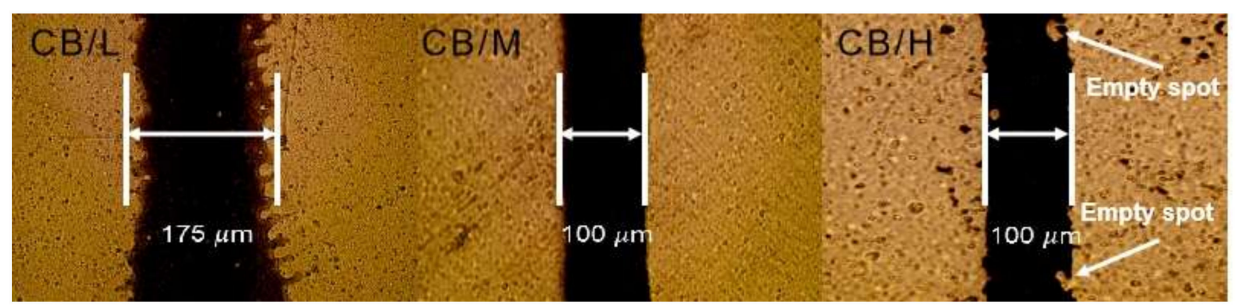

(c)

Figure 2. (a) Steady flow test and (b) PHS test to investigate the rheological behavior of CB/AgNPs paste with different ratios. (c) Microscope images of the printed pattern with different $\mathrm{CB}$ concentrations. PHS—peak hold step; CB—carbon black.

Table 1. Ag/CB ink viscosity at different shear rates, corresponding to different printing process steps.

\begin{tabular}{|c|c|c|c|c|c|c|c|c|c|c|c|c|}
\hline & $\begin{array}{c}0.1 \mathrm{~s}^{-1} \\
30 \mathrm{~s}\end{array}$ & $\begin{array}{c}200 \mathrm{~s}^{-1} \\
60 \mathrm{~s}\end{array}$ & $\begin{array}{c}0.1 \mathrm{~s}^{-1} \\
75 \mathrm{~s}\end{array}$ & $\begin{array}{c}\text { Recovery } \\
75 \mathrm{~s}\end{array}$ & $\begin{array}{c}0.1 \mathrm{~s}^{-1} \\
80 \mathrm{~s}\end{array}$ & $\begin{array}{l}\text { Recovery } \\
80 \mathrm{~s}\end{array}$ & $\begin{array}{c}0.1 \mathrm{~s}^{-1} \\
90 \mathrm{~s}\end{array}$ & $\begin{array}{l}\text { Recovery } \\
90 \mathrm{~s}\end{array}$ & $\begin{array}{c}0.1 \mathrm{~s}^{-1} \\
110 \mathrm{~s}\end{array}$ & $\begin{array}{c}\text { Recovery } \\
110 \mathrm{~s}\end{array}$ & $\begin{array}{c}0.1 \mathrm{~s}^{-1} \\
130 \mathrm{~s}\end{array}$ & $\begin{array}{c}\text { Recovery } \\
130 \mathrm{~s}\end{array}$ \\
\hline $\mathrm{L}$ & 1.66 & 0.51 & 0.78 & $47.0 \%$ & 0.81 & $48.7 \%$ & 0.85 & $51.1 \%$ & 0.94 & $56.5 \%$ & 0.97 & $58.4 \%$ \\
\hline $\mathrm{M}$ & 101.43 & 1.48 & 7.89 & $7.8 \%$ & 11.33 & $11.2 \%$ & 23.87 & $23.5 \%$ & 63.75 & $62.9 \%$ & 91.17 & $89.9 \%$ \\
\hline $\mathrm{H}$ & 501.47 & 2.15 & 90.21 & $18.0 \%$ & 153.63 & $30.6 \%$ & 266.42 & $53.1 \%$ & 376.44 & $75.1 \%$ & 447.62 & $89.3 \%$ \\
\hline
\end{tabular}

Six strain sensors with various line widths $(100$ and $300 \mu \mathrm{m})$ and lengths $(25,52$, and $78 \mathrm{~mm})$ at a fixed thickness of $110 \mu \mathrm{m}$ were fabricated, as shown in Figure 3a, to investigate the effect of pattern dimensions on the sensitivity. As the resistive-type sensor consists of electrodes, the electrical performance is important to attain a high sensitivity. Figure $3 \mathrm{~b}$ reveals the $I-V$ curves of the samples at a gradient voltage from 1 to $5 \mathrm{~V}$, where the current output changes in accordance with the increase in the applied voltage. Based on the linear slope of each line, the six different strain sensors showed a uniform conductivity. In addition, the sensor having a larger width and shorter length tended to show a higher current, which is reasonable based on Ohm's law. 


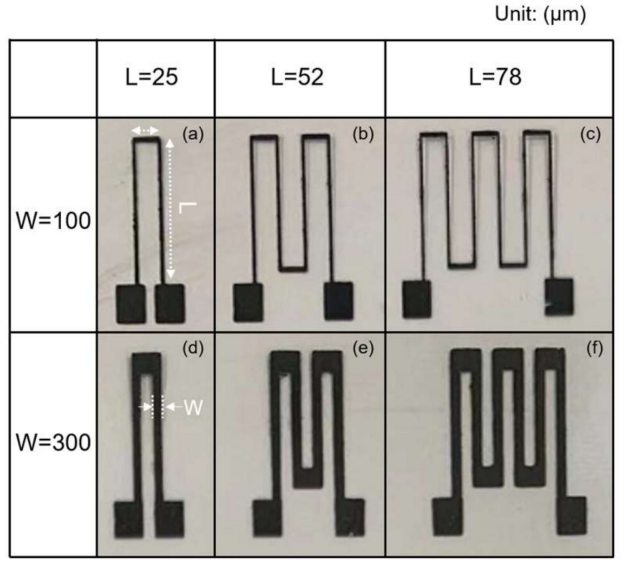

(a)

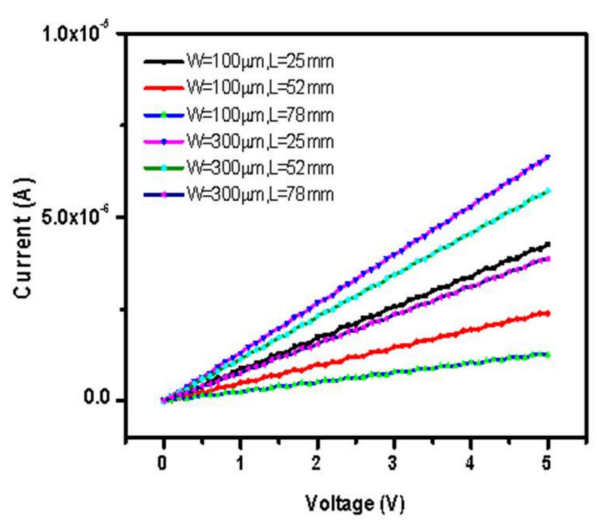

(b)

Figure 3. (a) Images of the screen-printed sensors with different length and width. (b) Measured resistance of the screen-printed $\mathrm{CB} / \mathrm{AgNPs}$ past lines at various dimensions.

An advantage of using a printed sensor is its controllable sensitivity. Figure 4a shows the GF of the sensors according to the applied strain. The GF was calculated as follows [12]:

$$
\begin{gathered}
G F=\frac{\Delta R}{R \Delta \varepsilon} \\
\varepsilon=\frac{h}{2 r} \\
c=2 r \times \sin \left(\frac{1}{2 r}\right)
\end{gathered}
$$

where $R$ refers to the initial resistance of the sensor under tension-free conditions; $\varepsilon$ indicates the tensile strain when a stress is applied to the sensor; and $\Delta R$ indicates the resistance change. The thickness of the sensor, $h$, and the radius of curvature, $R$, in the bending process are affected by the applied pressure, whereas the radius of curvature can be calculated through the arc length, 1 , and chord length, $c$, in the bending process.

It is observed that the strain-dependent responses increase monotonously with the increasing strain. With the application of strain in the range of $0.61 \%$ to $1.44 \%$ to the sensor, the GF determining the sensor sensitivity varied from 192.77 to 444.6 , which is the highest GF among the CB-based printed sensors under a large strain reported so far, to the best of our knowledge $[17,18,22-25]$. In addition, the sensitivity could be controlled by the dimension effect. Table 2 presents the excellent performance of the $\mathrm{CB} / \mathrm{AgNP}$ pastes in terms of sensitivity in comparison with the previous results in the literature [26-33]. The CB/AgNP paste could generate a high GF because the variation of junction resistance was severe under tension pressure, as shown in Figure $4 \mathrm{~b}$. The electrons in the conductive film can pass through a percolating lattice of overlapping nanomaterials, and the bending of the sensor can lead to a reduction in the overlapping areas or even a loss of electrical connections, increasing the resistance. 


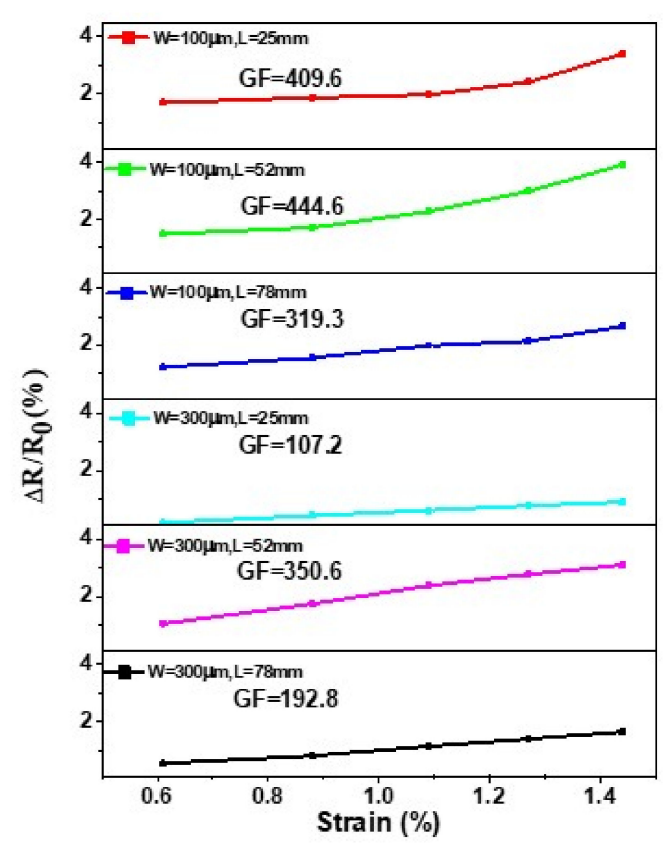

(a)

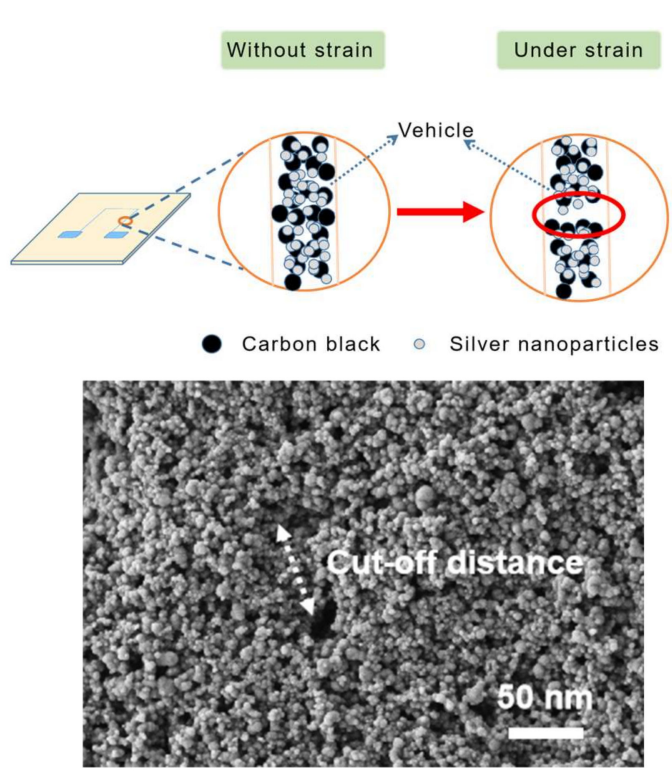

(b)

Figure 4. (a) Dynamic bending-release cycle response of the sensors for various strains $0.61-1.44 \%$ with the screen-printed $\mathrm{CB} / \mathrm{AgNP}$ lines at different lengths and various line widths. (b) Schematic diagram of sensing mechanism for $\mathrm{CB} / \mathrm{AgNP}$ paste and SEM image of surface for the screen-printed $\mathrm{CB} / \mathrm{AgNP}$ paste.

Table 2. Comparison of gauge factor (GF) of previous reported strain sensors based on carbon black.

\begin{tabular}{cccc}
\hline Material & Strain & Gauge Factor & Year \\
\hline CB/AgNPs composite & $0.61 \%-1.4 \%$ & $192.77-444.6$ & this work \\
Carbon black/natural & $0.1 \%$ & 43.2 & $2016[27]$ \\
thermoplastic elastomer & $10 \%$ & 31 & $2007[30]$ \\
(Evoprene)/carbon black & $10 \%$ & 15.75 & $2016[31]$ \\
CB/PDMS & $10 \%$ & 11.2 & $2015[28]$ \\
FCE/CB nanocomposites & $70 \%$ & 5 & $2018[33]$ \\
ChNCs-CB/NR & $60 \%$ & 3 & $2015[32]$ \\
CB/elastomer & $120 \%$ & 1.25 & $2017[29]$ \\
SWCNTs/CB & $0.14 \%$ & 741 & $2020[26]$ \\
PVC/CB & & &
\end{tabular}

The mechanical sensitivity and durability of the sensor were investigated to evaluate the properties of the sensor for application in wearable electronics. Figure 5a shows the continuous and uniform increase in the response according to the applied strain with different values, which reveals the calculated linearity as $R^{2}=0.9974$. Figure $5 b$ displays the high durability of the printed $C B / A g N P$ sensor over 1000 repetitive bending-releasing cycles at the applied strain of $0.275 \%$. All the responses were obtained without any noise during the bending cycles. The specific response is shown as an inset. In practice, sensors attached to a human body are subjected to various environmental conditions. Thus, a high stability is required under various conditions of temperature and humidity. Figure $5 \mathrm{c}$ shows a resistance change of $1.3 \%$ with the increase in temperature from 20 to $120^{\circ} \mathrm{C}$. In addition, a resistance change of $0.057 \%$ for the humidity of $70 \%$ is shown in Figure $5 \mathrm{~d}$. These results are mainly attributed to the intrinsic property of $\mathrm{CB}$ and its passivation layer [34]. However, an unstable performance was observed above the humidity of $70 \%$, which may be attributed to the high possibility of water penetration through the passive layer. 
(a)

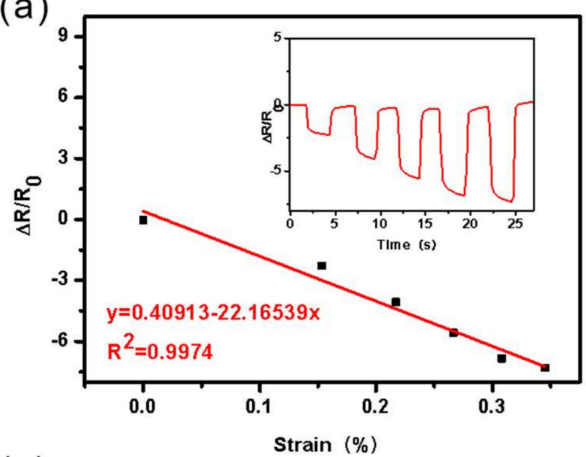

(c)

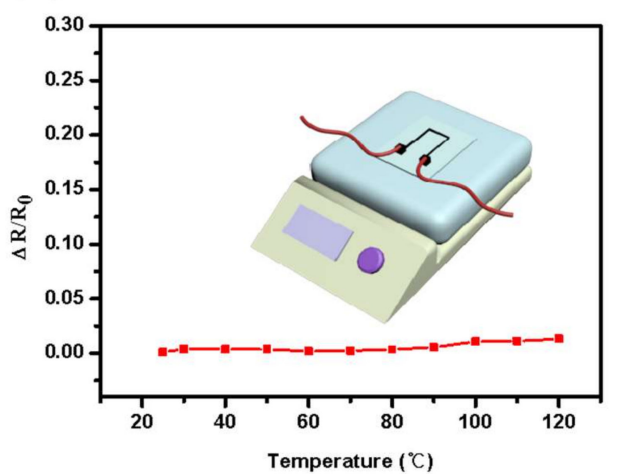

(b)

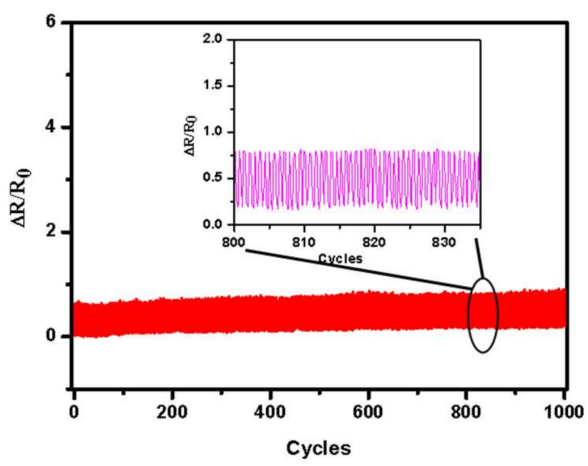

(d)

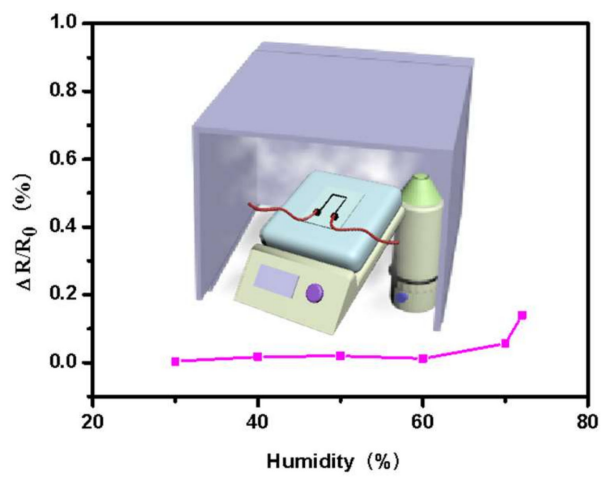

Figure 5. (a) Continuous progressive input of different strain. (b) Durability of composites under 1000 cycles with low tensile deformation. $\Delta R / R_{0}$ as a function of multiple bending and releasing cycles with $0.275 \%$ strain for $\mathrm{CB} / \mathrm{Ag}$ composites. $\Delta R$ refers to the resistance differences under bending and release, $R$ is the initial resistance in the relaxed state. Effect of temperature (c) and humidity (d) on the conductivity of the $\mathrm{CB} / \mathrm{Ag}(\mathrm{CB}-\mathrm{H})$ strain sensor.

As our $\mathrm{CB} / \mathrm{AgNP}$ strain sensors are highly flexible, scalable, and sensitive, they can be employed in wearable and flexible human motion detection platforms. Figure 6a shows the response of the sensor attached to a finger at a bending angle of $0^{\circ}-90^{\circ}$. In addition, the $\mathrm{CB} / \mathrm{AgNP}$ strain sensor was attached to a human neck to detect head rotation. It demonstrated a high sensitivity to reflect head rotation accurately, as shown in Figure 6b.

(a)

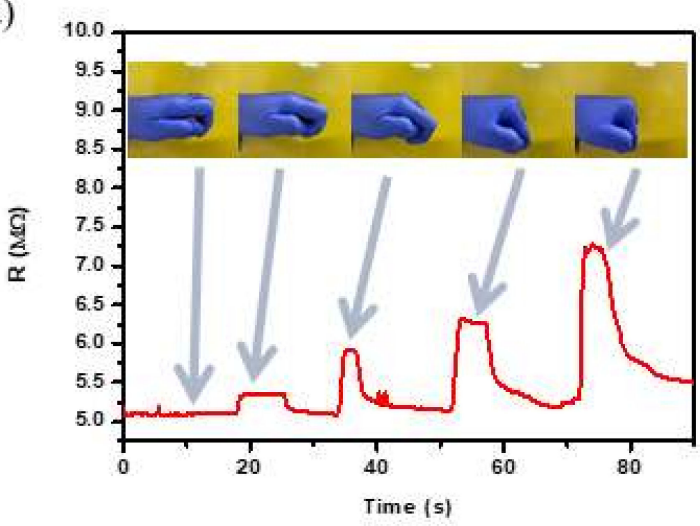

(b)

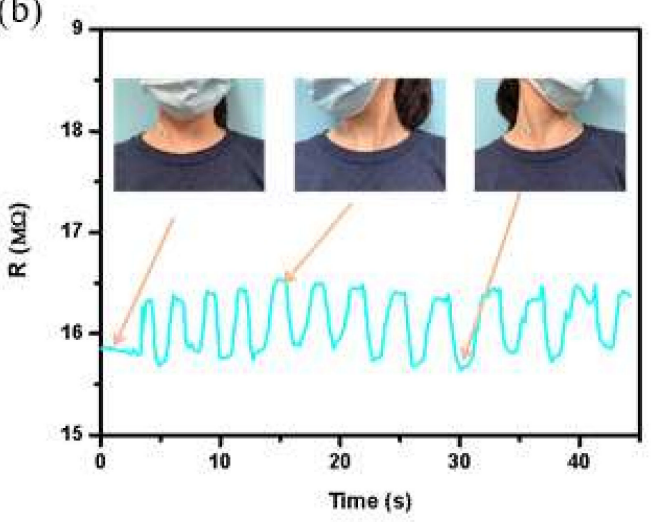

Figure 6. Human motion detection by the $\mathrm{CB} / \mathrm{AgNP}$ nanocomposite strain sensors. (a) Response of the $\mathrm{CB} / \mathrm{AgNP}$ strain sensor to the bending angles from $0^{\circ}$ to $90^{\circ}$. (b) Motion detection of head turning left to right. 


\section{Conclusions}

We proposed a new type of strain sensor based on $\mathrm{CB} / \mathrm{AgNP}$ composites using a screen-printing process. The rheological property of the pastes was investigated to determine the pattern fidelity in accordance with the ratio of CB and AgNPs. The electrical performances of the printed sensors with different widths and lengths were investigated, to evaluate the sensitivity of the strain sensors. Consequently, a GF of 444.6 was obtained for the printed sample with the line width of $100 \mu \mathrm{m}$ and the length of $52 \mathrm{~mm}$ at the applied strain ranging from $0.6 \%$ to $1.4 \%$. This is the highest sensitivity at this applied strain range among the printed sensors reported so far, to the best of our knowledge. The sample also showed a high sensing linearity of $\mathrm{R}^{2}=0.9974$ and a high bending stability of 1000 cycles. In particular, the sensor revealed a stable resistance change under tough environmental conditions, demonstrating its feasibility for wearable applications.

Author Contributions: Methodology, X.Q.; investigation, X.Q. and H.H.; writing-original draft preparation, X.Q. and S.L.; writing-review and editing, S.L.; supervision, B.H. All authors have read and agreed to the published version of the manuscript.

Funding: This study was supported by the National Research Foundation of Korea (NRF) grant funded by the Government of Korea (NRF-2018R1D1A1D07043938). This study was also supported by the Chung-Ang University Research Scholarship Grants in 2019.

Conflicts of Interest: The authors declare no conflict of interest.

\section{References}

1. Qi, X.; Li, X.; Jo, H.; Bhat, K.S.; Kim, S.; An, J.; Kang, J.W.; Lim, S. Mulberry paper-based graphene strain sensor for wearable electronics with high mechanical strength. Sens. Actuators A Phys. 2020, 301, 111697. [CrossRef]

2. Amjadi, M.; Kyung, K.U.; Park, I.; Sitti, M. Stretchable, Skin-Mountable, and Wearable Strain Sensors and Their Potential Applications: A Review. Adv. Funct. Mater. 2016, 26, 1678-1698. [CrossRef]

3. Patel, S.; Park, H.; Bonato, P.; Chan, L.; Rodgers, M. A review of wearable sensors and systems with application in rehabilitation. J. Neuroeng. Rehabil. 2012, 1-17. [CrossRef] [PubMed]

4. Zang, Y.; Zhang, F.; Di, C.A.; Zhu, D. Advances of flexible pressure sensors toward artificial intelligence and health care applications. Mater. Horiz. 2015, 2, 140-156. [CrossRef]

5. Jayathilaka, W.A.D.M.; Qi, K.; Qin, Y.; Chinnappan, A.; Serrano-García, W.; Baskar, C.; Wang, H.; He, J.; Cui, S.; Thomas, S.W.; et al. Significance of Nanomaterials in Wearables: A Review on Wearable Actuators and Sensors. Adv. Mater. 2019, 31, 1-21. [CrossRef] [PubMed]

6. Pardo, D.A.; Jabbour, G.E.; Peyghambarian, N. Application of screen printing in the fabrication of organic light-emitting devices. Adv. Mater. 2000, 12, 1249-1252. [CrossRef]

7. Liu, L.; Ye, X.; Wu, K.; Han, R.; Zhou, Z.; Cui, T. Humidity sensitivity of multi-walled carbon nanotube networks deposited by dielectrophoresis. Sensors 2009, 9, 1714-1721. [CrossRef]

8. Ali, S.; Hassan, A.; Hassan, G.; Bae, J.; Lee, C.H. All-printed humidity sensor based on gmethyl-red/methyl-red composite with high sensitivity. Carbon N. Y. 2016, 105, 23-32. [CrossRef]

9. Lee, J.; Cho, D.; Jeong, Y. A resistive-type sensor based on flexible multi-walled carbon nanotubes and polyacrylic acid composite films. Solid. State. Electron. 2013, 87, 80-84. [CrossRef]

10. Yi, W.; Wang, Y.; Wang, G.; Tao, X. Investigation of carbon black/silicone elastomer/dimethylsilicone oil composites for flexible strain sensors. Polym. Test. 2012, 31, 677-684. [CrossRef]

11. Moonen, P.F.; Yakimets, I.; Huskens, J. Fabrication of transistors on flexible substrates: From mass-printing to high-resolution alternative lithography strategies. Adv. Mater. 2012, 24, 5526-5541. [CrossRef] [PubMed]

12. Zirkl, M.; Sawatdee, A.; Helbig, U.; Krause, M.; Scheipl, G.; Kraker, E.; Ersman, P.A.; Nilsson, D.; Platt, D.; Bodö, P.; et al. An all-printed ferroelectric active matrix sensor network based on only five functional materials forming a touchless control interface. Adv. Mater. 2011, 23, 2069-2074. [CrossRef] [PubMed] 
13. Bae, S.; Kim, H.; Lee, Y.; Xu, X.; Park, J.S.; Zheng, Y.; Balakrishnan, J.; Lei, T.; Ri Kim, H.; Il Song, Y.; et al. Roll-to-roll production of 30-inch graphene films for transparent electrodes. Nat. Nanotechnol. 2010, 5, 574-578. [CrossRef]

14. Erath, D.; Filipović, A.; Retzlaff, M.; Goetz, A.K.; Clement, F.; Biro, D.; Preu, R. Advanced screen printing technique for high definition front side metallization of crystalline silicon solar cells. Sol. Energy Mater. Sol. Cells 2010, 94, 57-61. [CrossRef]

15. Lee, T.M.; Choi, Y.J.; Nam, S.Y.; You, C.W.; Na, D.Y.; Choi, H.C.; Shin, D.Y.; Kim, K.Y.; Il Jung, K. Color filter patterned by screen printing. Thin Solid Films 2008, 516, 7875-7880. [CrossRef]

16. Bao, Z.; Feng, Y.; Dodabalapur, A.; Raju, V.R.; Lovinger, A.J. High-Performance Plastic Transistors Fabricated by Printing Techniques. Chem. Mater. 1997, 9, 1299-1301. [CrossRef]

17. Park, K.; Seo, D.; Lee, J. Conductivity of silver paste prepared from nanoparticles, Colloids Surfaces A Physicochem. Eng. Asp. 2008, 313-314, 351-354. [CrossRef]

18. Faddoul, R.; Reverdy-bruas, N.; Blayo, A. Formulation and screen printing of water based conductive flake silver pastes.pdf. Mater. Sci. Eng. B Solid-State Mater. Adv. Technol. 2012, 177, 1053-1066. [CrossRef]

19. Krebs, F.C.; Jørgensen, M.; Norrman, K.; Hagemann, O.; Alstrup, J.; Nielsen, T.D.; Fyenbo, J.; Larsen, K.; Kristensen, J. A complete process for production of flexible large area polymer solar cells entirely using screen printing-First public demonstration. Sol. Energy Mater. Sol. Cells 2009, 93, 422-441. [CrossRef]

20. Hyun, W.J.; Secor, E.B.; Hersam, M.C.; Frisbie, C.D.; Francis, L.F. High-resolution patterning of graphene by screen printing with a silicon stencil for highly flexible printed electronics. Adv. Mater. 2015, 27, 109-115. [CrossRef]

21. Cao, X.; Chen, H.; Gu, X.; Liu, B.; Wang, W.; Cao, Y.; Wu, F.; Zhou, C. Screen printing as a scalable and low-cost approach for rigid and flexible thin-film transistors using separated carbon nanotubes. ACS Nano 2014, 8, 12769-12776. [CrossRef] [PubMed]

22. Zhang, W.; Liu, Q.; Chen, P. Flexible strain sensor based on carbon black/silver nanoparticles composite for humanmotion detection. Materials 2018, 11, 1836. [CrossRef] [PubMed]

23. Song, H.; Zhang, J.; Chen, D.; Wang, K.; Niu, S.; Han, Z.; Ren, L. Superfast and high-sensitivity printable strain sensors with bioinspired micron-scale cracks. Nanoscale 2017, 9, 1166-1173. [CrossRef]

24. Sorahan, T.; Harrington, J.M. A "lugged" analysis of lung cancer risks in UK carbon black production workers, 1951-2004. Am. J. Ind. Med. 2007, 50, 555-564. [CrossRef] [PubMed]

25. Faddoul, R.; Reverdy-Bruas, N.; Bourel, J. Silver content effect on rheological and electrical properties of silver pastes. J. Mater. Sci. Mater. Electron. 2012, 23, 1415-1426. [CrossRef]

26. Xiao, Y.; Jiang, S.; Li, Y.; Zhang, W. Highly sensitive printed crack-enhanced strain sensor as dual-directional bending detector. Smart Mater. Struct. 2020, 29, 045023. [CrossRef]

27. Wu, X.; Han, Y.; Zhang, X.; Lu, C. Highly Sensitive, Stretchable, and Wash-Durable Strain Sensor Based on Ultrathin Conductive Layer@ Polyurethane Yarn for Tiny Motion Monitoring. ACS Appl. Mater. Interfaces 2016. [CrossRef]

28. Mi, M.; Pissis, P.; Kraj, J. Study of the reinforcing mechanism and strain sensing in a carbon black filled elastomer. Compos. Part B Eng. 2015, 80, 20-26. [CrossRef]

29. Guo, X.; Huang, Y.; Zhao, Y.; Mao, L.; Gao, L. Highly stretchable strain sensor based on SWCNTs/CB synergistic conductive network for Highly stretchable strain sensor based on SWCNTs/CB synergistic conductive network for wearable human-activity monitoring and recognition. Smart Mater. Struct. 2017, 26, 095017. [CrossRef]

30. Koncar, V.; Lewandowski, M.; Dufour, C. Design and Development of a Flexible Strain Sensor for Textile Structures Based on a Conductive Polymer Composite. Sensors 2007, 7, 473-492.

31. Zheng, Y.; Li, Y.; Li, Z.; Wang, Y.; Dai, K.; Zheng, G.; Liu, C. The effect of fi ller dimensionality on the electromechanical performance of polydimethylsiloxane based conductive nanocomposites for fl exible strain sensors. Compos. Sci. Technol. 2017, 139, 64-73. [CrossRef]

32. Dubey, K.A.; Mondal, R.K.; Grover, V.; Bhardwaj, Y.K.; Tyagi, A.K. Physical Development of a novel strain sensor based on fluorocarbon-elastomeric nanocomposites: Effect of network density on the electromechanical properties. Sensors Actuators A. Phys. 2015, 221, 33-40. [CrossRef] 
33. Liu, Y.; Wu, F.; Zhao, X.; Liu, M. High-Performance Strain Sensors Based on Spirally Structured Composites with Carbon Black, Chitin Nanocrystals, and Natural Rubber. ACS Sustain. Chem. Eng. 2018, 6, 10595-10605. [CrossRef]

34. Schmid, P.; Orfert, M.; Vogt, M. Plasma deposition of Si-N and Si-O passivation layers on three-dimensional sensor devices. Surf. Coat. Technol. 1998, 98, 1510-1517. [CrossRef] 